\title{
Numerical Study of the Thermal Performance of Three Roof Models in Hot and Dry Climates
}

\section{Windé Nongué Daniel Koumbem ${ }^{1 *}$, Issaka Ouédraogo², Wend Dolean Arsène Ilboudo², Pèlèga Florent Kieno ${ }^{1}$}

\author{
${ }^{1}$ Universite Joseph Ki-Zerbo, Ouagadougou, Burkina Faso \\ ${ }^{2}$ Institut de Recherche en Sciences Appliquées et Technologies, Ouagadougou, Burkina Faso \\ Email: *koumbemdaniel@gmail.com
}

How to cite this paper: Koumbem, W.N.D. Ouédraogo, I., Ilboudo, W.D.A. and Kieno, P.F. (2021) Numerical Study of the Thermal Performance of Three Roof Models in Hot and Dry Climates. Modeling and $\mathrm{Nu}$ merical Simulation of Material Science, 11, $35-46$.

https://doi.org/10.4236/mnsms.2021.112003

Received: April 20, 2021

Accepted: April 27, 2021

Published: April 30, 2021

Copyright $\odot 2021$ by author(s) and Scientific Research Publishing Inc. This work is licensed under the Creative Commons Attribution International License (CC BY 4.0).

http://creativecommons.org/licenses/by/4.0/

\begin{abstract}
The thermal performance of three roofing models: tile, corrugated and earth terrace is numerically analyzed. The mathematical equations which govern the three roofing models are established by the electrical method of analogies. These equations are discretized by an implicit finite difference method and solved by the Gauss-Seidel algorithm. We analyze the influences of geometric parameters (Xlo, Xlarg, $\alpha$ and Ep) on the evolution of the temperatures of the different environments of our three roof models. In particular, we have shown that the effectiveness of a roof in reducing the temperature inside a room is linked to its physical properties. The results obtained that for the same geometric parameters, the earth roof terrace and the earth tile roof compared to the corrugated metal roof improve thermal comfort by lowering the interior temperature of $5^{\circ} \mathrm{C}$ and $4.6^{\circ} \mathrm{C}$.
\end{abstract}

\section{Keywords}

Thermal Performance, Roof, Room Temperature

\section{Introduction}

Burkina Faso, a country with low energy resources, is characterized by a hot and dry climate that favours the transfer of heat inside the habitat, hence the thermal discomfort. The rate of sweating exceeds $80 \%$ during the hot periods of the year. To improve thermal comfort, we proceed by active air treatment methods, such as air conditioners. These methods generate excessive energy consumption. Faced with this, it is imperative to develop other methods of ventilation by natural convection. To do this, several possibilities can be considered, notably by taking into account in the design of the roof envelope. Thus, the search for thermal comfort 
through the improvement of the housing envelope is a very important area of research and has undergone great development in recent years. Several numeri$\mathrm{cal}$ and experimental studies have been carried out on the search for thermal comfort by improving the roof envelope. Among these studies, [1] studied a passive cooling system using a radio-evaporative roof in a hot and arid climate. It has shown that this type of roof reduces the thermal loads of the habitat by $75 \%$ during warm periods. [2] through simulations of the thermal behavior of the diode roof has shown that it reduces the interior temperature of the habitat and generates natural ventilation. A modelling of a bioclimatic roof for passive airconditioning of a typical habitat in Burkina has shown that a north-facing roof south inclined at an angle of $45^{\circ}$ from the horizontal, gives an average indoor air temperature of $31.3^{\circ} \mathrm{C}$ during the warmest hours. At an angle of $55^{\circ}$, the temperature decreases to $29^{\circ} \mathrm{C}$ [3]. The experimental study of the thermal rehabilitation of a room in an Arid zone-case of GHARDIA. [4] showed that by placing 8 $\mathrm{cm}$ thick polystyrene glue to a $7 \mathrm{~cm}$ thick plasterboard on the roof of the building. Room and west walls exposed to the sun and north exposed to the wind reduces the effect of solar radiation on the studio. The author also shows the decrease in temperature between $8^{\circ} \mathrm{C}$ and $10^{\circ} \mathrm{C}$ for periods of heat. [5] through a theoretical and experimental study of heat transfers in a round hut with a geobeton roof in the city of Abidjan, show that for a closed hut, geobeton improves comfort by lowering the ambient temperature by $0.5^{\circ} \mathrm{C}$ to $2^{\circ} \mathrm{C}$. Through an evaluation study of the thermal comfort of public buildings: case of the architecture department of Tamda (Tizi-Ouzou), [6] shows that the interior temperature of the workshops depends on the orientation and the degree of exposure of facades to solar radiation. [7] studied the impact of thermal inertia on hygrothermal comfort and building energy consumption: the case of the colonial era dwelling in Guelma. He shows through this study that the roof alone encompasses $30 \%$ of total heat loss. A study of the influence of local insulating roofing materials on the air conditioning loads of a clay-straw detached house was carried out by [8]. The results obtained by these authors show that the clay-straw mixture reduces the air conditioning requirements compared to the clay wall by around $8 \%$. They also show that a $1.5 \mathrm{~cm}$ thick insulation for the roof saves around $8.3 \%$ on climatic loads. The indoor temperature levels achieved in an un-air conditioned building depend mainly on the outdoor temperature, internal heat gains, solar gains, ventilation and thermal inertia [9] [10] [11]. In this work, we digitally study the thermal behavior of three roof models: tile, sheet metal and roof terrace on the thermal comfort of the habitat in hot and dry climates. At the end of this study, a roof model suitable for countries with hot and dry climates will be proposed in order to improve thermal comfort in buildings.

\section{Description of Roof Models}

The tile roof has been used in Burkina Faso for about ten years. It is used in modern constructions, of size $0.3 \mathrm{~m} \times 0.15 \mathrm{~m}$. The interior consists of a 0.005 - 
$0.010 \mathrm{~m}$ thick wood ceiling that reduces heat transfer by conduction into the habitat as shown in Figure 1(a). The corrugated iron roof was introduced into the country by French settlers. It is widely used, especially in urban centers. It consists of a sheet of $3 \mathrm{~m}$ long and $0.5 \mathrm{~m}$ wide with a thickness varying from $0.003 \mathrm{~m}$ to $0.015 \mathrm{~m}$. Inside some habitats there is a $0.005-0.010 \mathrm{~m}$ thick wooden ceiling which also reduces heat transfer by conduction into the habitat as shown in Figure 1 (b). The earth roof terrace (Figure $1(c)$ ) is a very old technique used in rural buildings. It consists of tree trunks 3 to $4 \mathrm{~m}$ long and 5 to $10 \mathrm{~m}$ in diameter. It is then covered with a mixture of grass clay and millet fiber. The mixture is then homogenized with the help of pillions and hands. It obeys endogenous techniques which is intended that the roof terrace.

\section{Mathematical Formulation of Equations Governing Heat Transfers in the Three Roof Models}

To simulate the thermal behavior of our three roof models, we divide the length $(L)$ of the roof into several dummy sections according to the direction $(X)$. To write the thermal balance of each slice of the length $(L)$, we proceed by the method of analogies that exists between thermal and electrical transfers. Hypothetically, we assume that there is no mass transfer in the three roof models, and the air movement is one-dimensional $(X)$. Also, we assume that the physical properties of air and roofing materials are constant (Table 1). The application of ohm

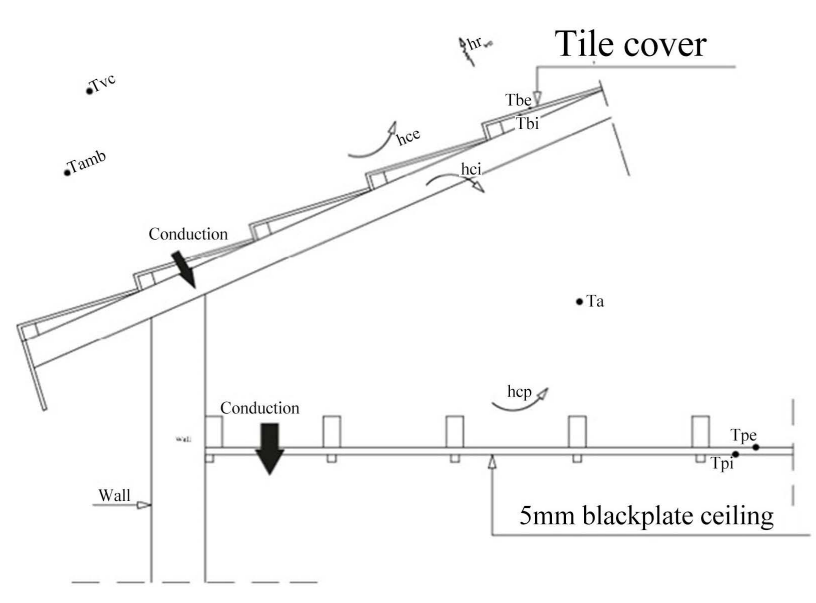

(a)

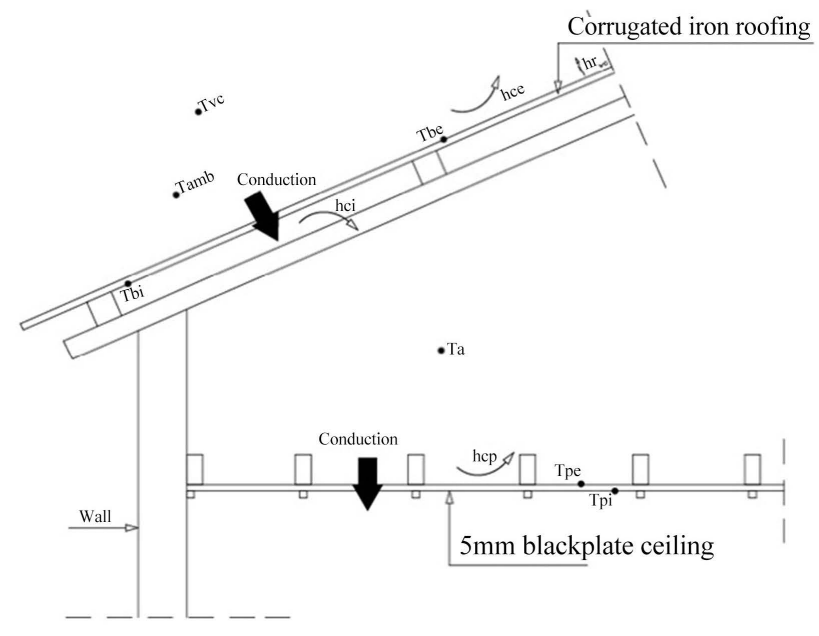

(b)

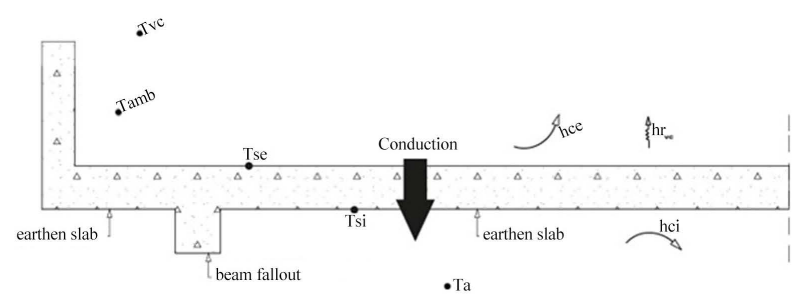

(c)

Figure 1. Physical roofs models studied. 
Table 1. Physical properties of materials.

\begin{tabular}{ccccc}
\hline material & $\begin{array}{c}\text { Density }(\rho) \\
\left(\mathrm{kg} / \mathrm{m}^{3}\right)\end{array}$ & $\begin{array}{c}\text { Calorific capacity }(C P) \\
\left(\mathrm{J} \cdot \mathrm{kg}^{-1} \cdot \mathrm{K}^{-1}\right)\end{array}$ & $\begin{array}{c}\text { Thermal conductivities }(\lambda) \\
\left(\mathrm{W} / \mathrm{m}^{-1} \cdot \mathrm{K}^{-1}\right)\end{array}$ & $\begin{array}{c}\text { Emissivity } \\
\mathcal{E}\end{array}$ \\
\hline Clay tile & 780 & 1800 & 0.8 & 0.6 \\
Compacted earth & 1500 & 1700 & 0.658 & 0.834 \\
Aluminium & 2750 & 936 & 204 & 0.09 \\
ceiling & 500 & 3000 & 0.15 & - \\
\hline
\end{tabular}

law allows us to write the thermal balance equations according to the direction $(X)$. The thermal balance equations are applied to the three roof models studied. To avoid the repetition of the heat balance equations in the text, we present the equations of the tile roof, which are also valid for the corrugated roof and the terrace roof. Indeed, these are the three modes of transfer which are convection, conduction and radiation.

\section{Roof in Tiles}

The external face

$$
\begin{aligned}
\frac{M_{c e} \cdot C p_{c e}}{S} \frac{\partial T_{c e}}{\partial t}= & \frac{\lambda_{c e}}{E p_{c e}}\left(T_{c e}-T_{c i}\right)+h c_{e}\left(T_{a m b}-T_{c e}\right) \\
& +h r_{v c}\left(T_{v c}-T_{c e}\right)+h r_{s o l}\left(T_{s o l}-T_{c e}\right)
\end{aligned}
$$

The inside face

$$
\frac{M_{c e} C p_{c e}}{S} \frac{\partial T_{c i}}{\partial t}=\frac{\lambda_{c e}}{E p_{c e}}\left(T_{c e}-T_{c i}\right)+h c_{i}\left(T_{a}-T_{c i}\right)
$$

Air in the roof

$$
\frac{M_{a} C p_{a}}{S} \frac{\partial T_{a}}{\partial t}=h c_{i}\left(T_{c i}-T_{a}\right)+h c_{p}\left(T_{p e}-T_{a}\right)
$$

Upper side of ceiling

$$
\frac{M_{p} C p_{p}}{S} \frac{\partial T_{p}}{\partial t}=\frac{\lambda_{p}}{E p_{p}}\left(T_{p e}-T_{p i}\right)+h c_{p}\left(T_{a}-T_{p e}\right)
$$

\section{Discretization of the Equations of Our Roof Models}

The discretization of Equations (1) to (4) is expressed in the form:

External wall of the roof

$$
\begin{aligned}
\frac{M_{c e} \cdot C p_{c e}}{S} \cdot \frac{T_{c e}^{t+1}-T_{c e}^{t}}{\Delta t}= & \frac{\lambda_{c e}}{E p_{c e}}\left(T_{c e}^{t}-T_{c i}^{t}\right)+h c_{e}\left(T_{a m b}^{t}-T_{b e}^{t}\right) \\
& +h r_{v}\left(T_{v c}^{t}-T_{c e}^{t}\right)+h r_{s o}\left(T_{s o}^{t}-T_{c e}^{t}\right) \\
T_{c e}^{t+1}= & \left(1+\frac{\lambda_{c e} \cdot S \cdot \Delta t}{E p_{c e} \cdot M_{c e} \cdot C p_{c e}}-\frac{h c_{e} \cdot S \cdot \Delta t}{M_{c e} \cdot C p_{c e}}-\frac{h r_{v} \cdot S \cdot \Delta t}{M_{c e} \cdot C p_{c e}}-\frac{h r_{s o} \cdot S \cdot \Delta t}{M_{c e} \cdot C p_{b e}}\right) T_{c e}^{t} \\
- & \frac{\lambda_{c e} \cdot S \cdot \Delta t}{E p_{c e} \cdot M_{c e} \cdot C p_{c e}} T_{b i}^{t}+\frac{h c_{e} \cdot S \cdot \Delta t}{M_{b e} \cdot C p_{c e}} T_{a m b}^{t} \\
+ & \frac{h r_{v} \cdot S \cdot \Delta t}{M_{c e} \cdot C p_{c e}} T_{v c}^{t}+\frac{h r_{s o} \cdot S \cdot \Delta t}{M_{c e} \cdot C p_{c e}} T_{s o}^{t}
\end{aligned}
$$

Inside the roof face 


$$
\begin{aligned}
& \frac{M_{c e} \cdot C p_{c e}}{S} \cdot \frac{T_{c i}^{t+1}-T_{c i}^{t}}{\Delta t}=\frac{\lambda_{c e}}{E p_{c e}}\left(T_{c e}^{t}-T_{c i}^{t}\right)+h c_{i}\left(T_{a}^{t}-T_{c i}^{t}\right) \\
T_{c i}^{t+1}= & \frac{\lambda_{b e} \cdot S \cdot \Delta t}{E p_{c e} \cdot M_{c e} \cdot C p_{c e}} T_{b e}^{t}+\left(1-\frac{\lambda_{c e} \cdot S \cdot \Delta t}{E p_{b e} \cdot M_{c e} \cdot C p_{c e}}-\frac{h c_{i} \cdot S \cdot \Delta t}{M_{c e} \cdot C p_{c e}}\right) T_{c i}^{t} \\
& +\frac{h_{c i} \cdot S \cdot \Delta t}{M_{c e} \cdot C p_{c e}} T_{a}^{t}
\end{aligned}
$$

Air in the roof

$$
\begin{gathered}
\frac{M_{a} \cdot C p_{a}}{S} \cdot \frac{T_{a}^{t+1}-T_{a}^{t}}{\Delta t}=h c_{i}\left(T_{c i}^{t}-T_{a}^{t}\right)+h c_{p}\left(T_{p, \text { sup }}^{t}-T_{a}^{t}\right) \\
T_{a}^{t+1}=\frac{h c_{i} \cdot S \cdot \Delta t}{M_{a} \cdot C p_{a}} T_{p i}^{t}+\left(1-\frac{h c_{i} \cdot S \cdot \Delta t}{M_{a} \cdot C p_{a}}-\frac{h c_{p} \cdot S \cdot \Delta t}{M_{a} \cdot C p_{a}}\right) T_{a}^{t}+\frac{h c_{p} \cdot S \cdot \Delta t}{M_{a} \cdot C p_{a}} T_{p e}^{t}
\end{gathered}
$$

Upper side of ceiling

$$
\begin{aligned}
\frac{M_{p} \cdot C p_{p}}{S} & \cdot \frac{T_{p e}^{t+1}-T_{p i}^{t}}{\Delta t}=\frac{\lambda_{p}}{E p_{p}}\left(T_{p e}^{t}-T_{p i}^{t}\right)+h_{c p}\left(T_{a}^{t}-T_{p e}^{t}\right) \\
T_{p e}^{t+1}= & \left(1+\frac{\lambda_{p} \cdot S \cdot \Delta t}{M_{p} \cdot C p_{p} \cdot E p_{p}}-\frac{h c_{p} \cdot S \cdot \Delta t}{M_{p} \cdot C p_{p}}\right) T_{p e}^{t} \\
& -\frac{\lambda_{p} \cdot S \cdot \Delta t}{M_{p} \cdot C p_{p} \cdot E p_{p}} T_{p i}^{t}+\frac{h c_{p} \cdot S \cdot \Delta t}{M_{p} \cdot C p_{p}} T_{a}^{t}
\end{aligned}
$$

\section{Numerical Resolution Method}

The Equations (1)-(4) are discretized (5)-(8) using an explicit method of finite differences. This method transforms the transfer equations into a system of algebraic equations which are solved by the Gauss-Seidel method. The coefficients of heat transfer by natural convection and radiation depend on the temperatures of the different environments which are unknown [12]. Also, an iterative calculation is required. An arbitrary value, taken equal to the ambient temperature, is assigned to the temperatures of the different environments for the calculation of the transfer coefficients which allows the resolution of the system of algebraic equations. The obtained temperatures are then compared with the arbitrary values thus formed by the distribution of the temperatures in the different sections of the roof. If the deviation satisfies the desired precision err $=10^{-3}$, the calculated temperature is displayed otherwise, the arbitrary value is replaced by the calculated temperatures and the calculation is repeated until the satisfaction of the precision.

\section{Numerical Results and Discussions}

We present the numerical results of our calculations for the three roof models, in the form of temperature curves in the different roof environments. Thus, Figure 2 shows the temperature curves of the different environments of the roof tile. For our typical day which is from $8 \mathrm{~h}$ to $20 \mathrm{~h}$, the curve of the external wall exposed to the sun grows at $10 \mathrm{~h}$ from $311.7 \mathrm{~K}$ until it reaches its maximum at $13 \mathrm{~h}$ 
or $314.6 \mathrm{~K}$; after this hour, we observe a drop in temperature which reaches $306.4 \mathrm{~K}$ at $6 \mathrm{pm}$. For the same hours, the internal wall curve shows the values $310.9 \mathrm{~K}, 313.8 \mathrm{~K}$ and $305.3 \mathrm{~K}$. As for the air contained in the roof, the temperature also increased from $310.6 \mathrm{~K}$ to $313.5 \mathrm{~K}$ and decreased to $305.1 \mathrm{~K}$. These differences in temperature between the roof environments may be due to the physical properties of the materials. Figure 3 shows the evolution of the temperatures of the different environments of the corrugated roof during the same typical day. We observe an increase in the temperature of the outer wall from $10 \mathrm{~h}$ to $13 \mathrm{~h}$ respectively $316.6 \mathrm{~K}$ until $319.5 \mathrm{~K}$; after $13 \mathrm{~h}$, we notice a decrease in temperature which reaches $311.6 \mathrm{~K}$ at $18 \mathrm{~h}$. We also observe an increase in the temperature curve of the internal wall from $316.2 \mathrm{~K}$ at $10 \mathrm{~h}$ to reach $319.1 \mathrm{~K}$ at $13 \mathrm{~h}$ its maximum value, time at which the curve begins to decrease and reaches $311 \mathrm{~K}$ at $18 \mathrm{~h}$. We also notice a temperature growth of the confined air in this model of 10 $\mathrm{h}$ and $13 \mathrm{~h}$, being $315.7 \mathrm{~K}$ and $318.6 \mathrm{~K}$; and a temperature decrease after $13 \mathrm{~h}$ until reaching $310.4 \mathrm{~K}$ at $18 \mathrm{~h}$. These small temperature differences between the corrugated roof environments are due to the high thermal conductivity of aluminum. Figure 4 illustrates the evolution of the temperatures of the different

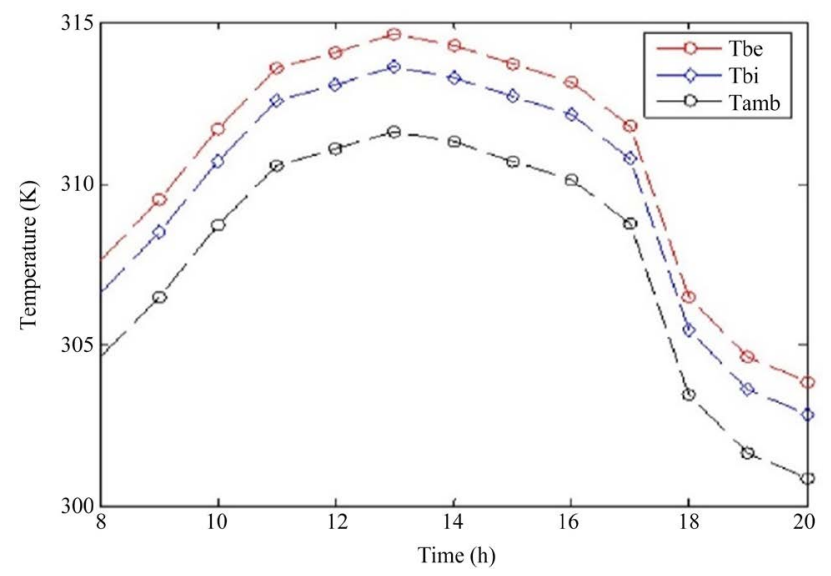

Figure 2. Evolution of the temperatures of the different environments of the roof tile as a function of time.

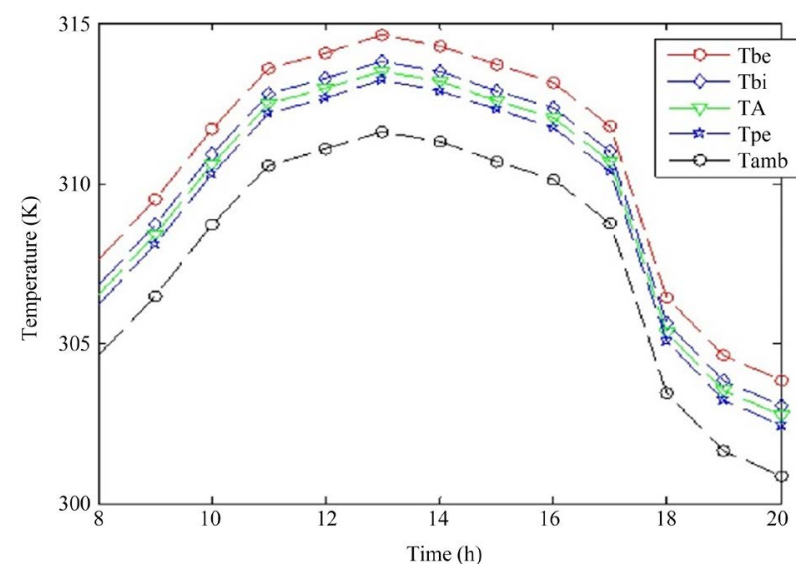

Figure 3. Evolution of temperatures of the different environments of the corrugated roof as a function of time. 


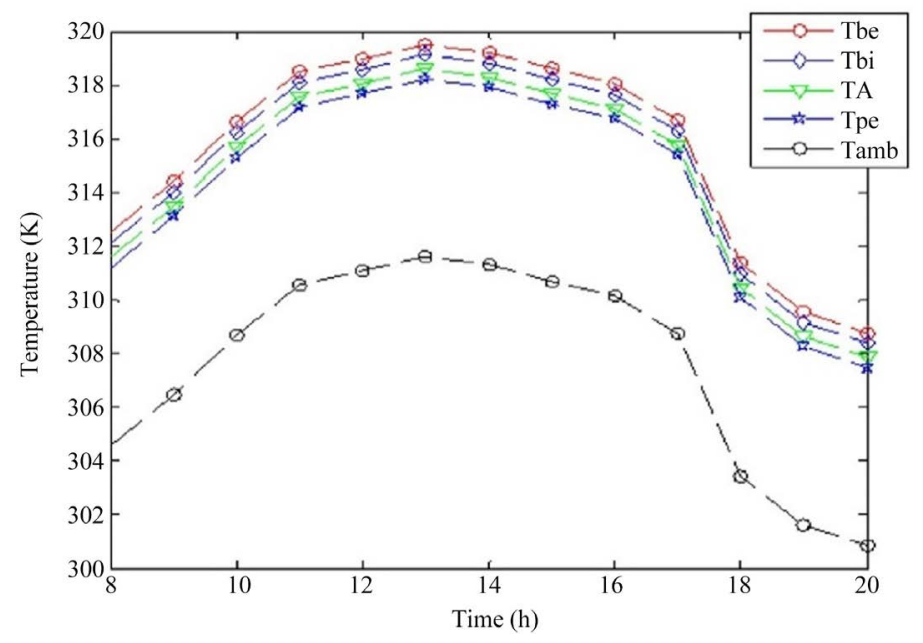

Figure 4. Evolution of the temperatures of the different environments of the roof terrase as a function of time.

environments of the roof terrace during our typical day. We observe an increase in the temperature curves of the different environments from $10 \mathrm{~h}$ until reaching the maximum values at $13 \mathrm{~h}$. After $13 \mathrm{~h}$ the temperature starts to drop. At the external wall of this roof, we have a temperature of $311.7 \mathrm{~K}$ at $10 \mathrm{~h}$ which evolves and reaches its maximum value at $13 \mathrm{~h}$ or $314.6 \mathrm{~K}$, then it drops to $306.4 \mathrm{~K}$ at 18 h. For the inner wall, the temperatures are $310.7 \mathrm{~K}$ at 10:00, $313.6 \mathrm{~K}$ at 13:00 and $305.4 \mathrm{~K}$ at 18:00. These temperature differences are due to the thermal conductivity of the earth material. By comparing the temperature curves of the Figures $2-4$, we find that the roof terrace presents the lowest temperatures followed by the roof tiles.

Influence of calculation parameters on temperature distributions.

$>$ To find the optimal parameters of our three roof models, we vary the following parameters. length $(X l o)$, width $(X l a r g)$, inclination $(\alpha)$ and thickness of materials $(E P)$.

The curves of the Figures 5-10 show the influence of the geometric parameters (Xlo, Xlarg, $\alpha$ and $E p$ ) on the evolution of the temperatures of the different environments of our three roof models.

The curves in Figure 5 and Figure 8 correspond to the temperatures of the different environments of the roof tiles. The temperature of the outer wall is identical for both figures and at a maximum value of $314.6 \mathrm{~K}$ at $13 \mathrm{~h}$. Internal wall and confined air temperatures vary from one figure to another. They are 313.4 K and 313.1 K respectively for Figure 5, 313.6 K and 313.3 K for Figure 8. The curves in Figure 6 and Figure 9 show the temperatures of the various environments of the corrugated iron roof. The temperature of its wall exposed to solar radiation is identical for the two figures of maximum value $319.4 \mathrm{~K}$ at $13 \mathrm{~h}$. For the same time, the internal wall and confined air temperatures vary from one figure to another. The maximum temperatures for these media are $318.6 \mathrm{~K}$ and 317.8 K for Figure 6, 318.8 K and $318 \mathrm{~K}$ for Figure 9, respectively. 


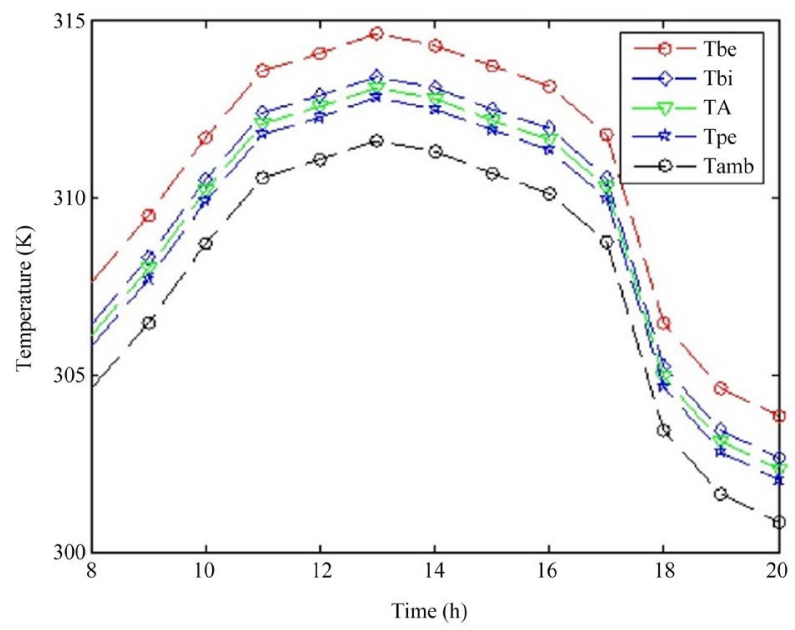

Figure 5. Evolution of the temperatures of the different environments of the roof tile as a function of time. Influence of geometric dimensions.

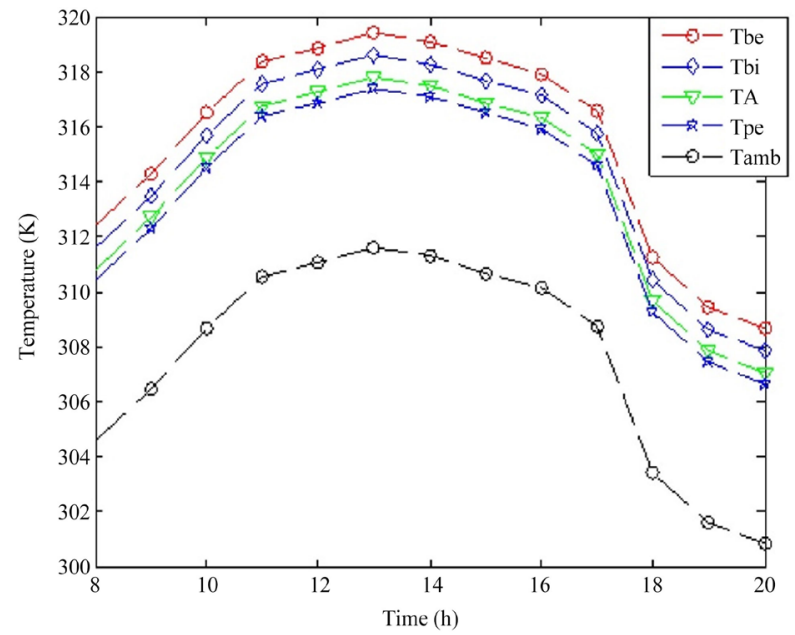

Figure 6. Temperature changes of different environments of the corrugated roof as a function of time. Influence of geometric dimensions.

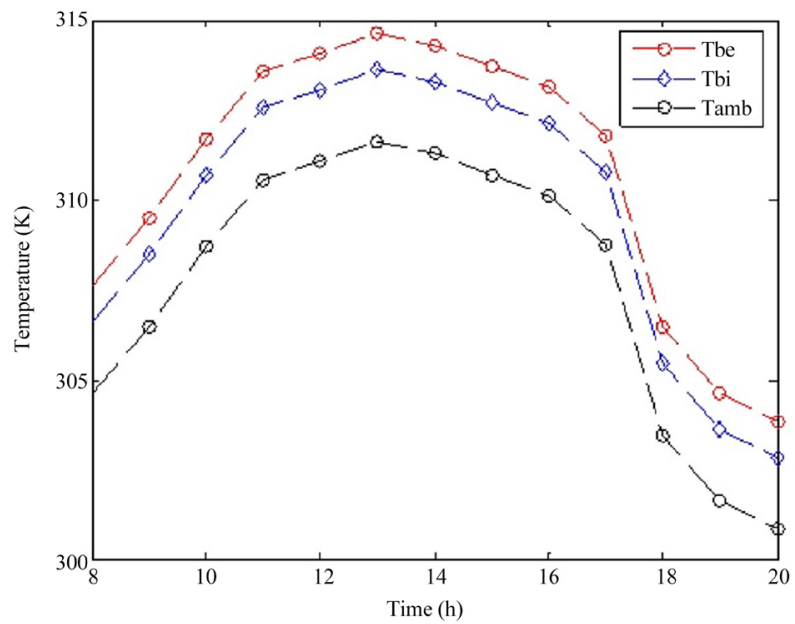

Figure 7. Evolution of temperature of the different environments of the roof terrace as a function of time. Influence of geometric dimensions. 


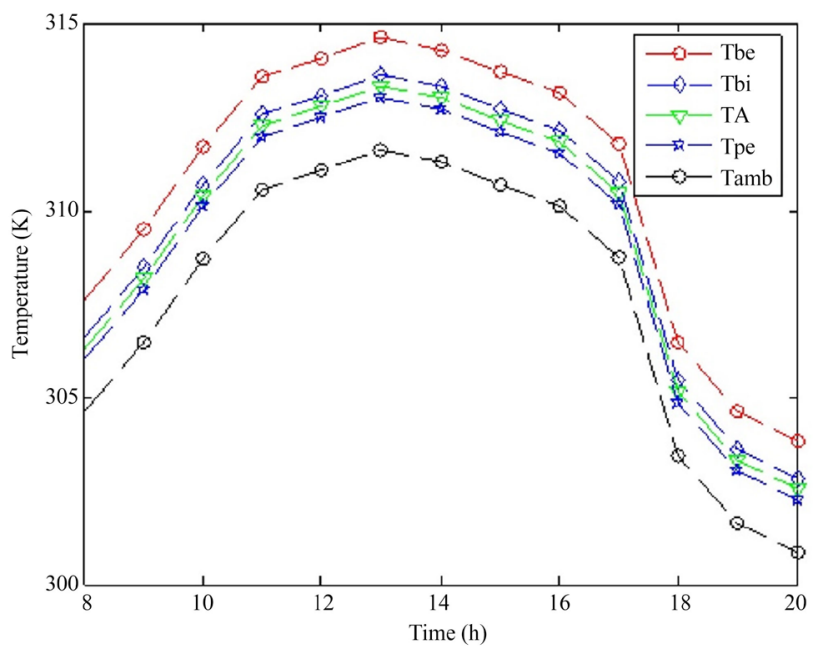

Figure 8. Evolution of the temperatures of the different environments of the roof tile as a function of time. Influence of geometric dimensions.

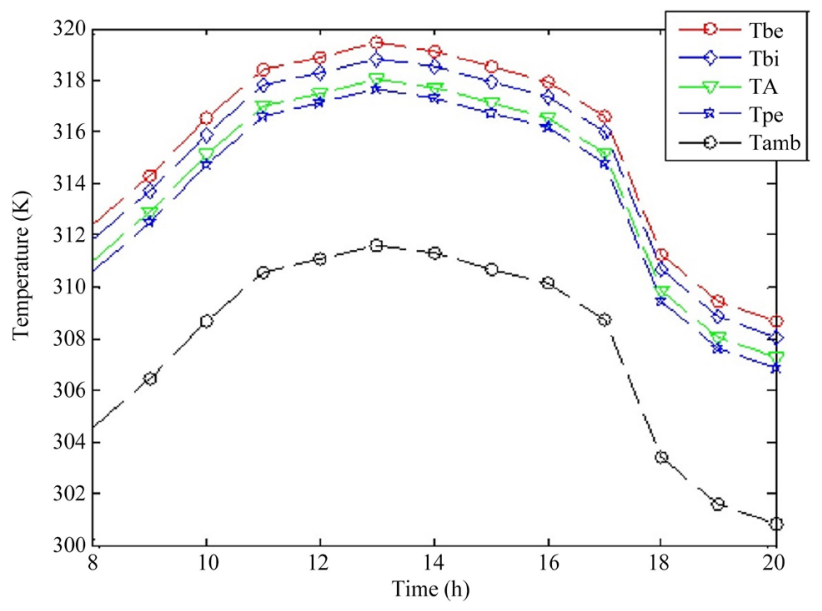

Figure 9. Temperature changes of different environments of the corrugated roof as a function of time. Influence of the geometric dimensions.

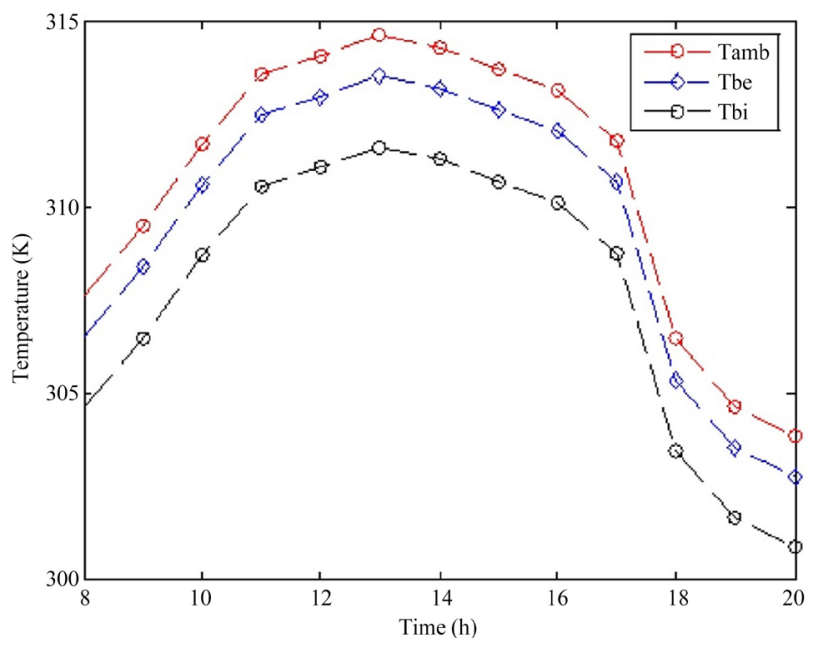

Figure 10. Temperature change of the different environments of the roof terrace as a function of time. Influence of geometric dimensions. 
At the level of the roof terrace Figure 7 and Figure 10, we note that the temperature of the external wall is identical for the three figures of maximum value $314.6 \mathrm{~K}$ at $13 \mathrm{~h}$. This value is similar to that of Figure 5 and Figure 8 of roof tile. The internal wall temperature differs from roof to roof and is $313.4 \mathrm{~K}$ for Figure 7, 313.5 K for Figure 10. Examination of the curves of the Figures 5-10 shows that the geometric parameters influence the temperatures of the different environments of our three roofs. The temperatures of the internal walls and the confined air decrease for ever greater parameters.

By comparing the curves of the Figures 5-10, we find that the curves of Figure 6, Figure 9 of the roof corrugated sheet shows the highest temperatures.

For the following parameters: Xlo $=2.35 \mathrm{~m} ; X \operatorname{larg}=1.75 \mathrm{~m} ; \alpha=35^{\circ} ; E p=0.3$ $\mathrm{m}$, we obtain the following results:

By varying the parameters: Xlo $=3.15 \mathrm{~m} ;$ Xlarg $=2.2 \mathrm{~m} ; \alpha=20^{\circ} ; E p=0.2 \mathrm{~m}$, we obtain the following results.

\section{Conclusions}

The obvious interest of the roof on the reduction of the internal temperature in a room, we have proceeded to the development of mathematical models based on the electric analogy that can predict the temperature of the different roof environments. These models integrate both meteorological data, geometric and physical parameters of the materials of our roof models. Through this study, we have provided an analysis on the thermal behavior of three roof models used in the Burkinabè habitat. A good use of the numerical method allows the thermal characterization of roofing materials.

At the end of this study, we show that the main causes of thermal discomfort in the habitat remain certain roofing materials with high thermal conductivity such as sheet metal, as well as the geometric shape. Thus, the corrugated roof shows a maximum temperature of $318.8 \mathrm{~K}$ for a thermal conductivity of $\lambda_{\text {Aluminum }}=204 \mathrm{~W} / \mathrm{K}^{-1} \cdot \mathrm{m}^{-1}$. The terracotta tile roof shows a maximum temperature of $313.6 \mathrm{~K}$ for a thermal conductivity of $\lambda_{\text {terracotta }}=0.8 \mathrm{~W} / \mathrm{K}^{-1} \cdot \mathrm{m}^{-1}$. As for the compressed earth roof deck, we observe a maximum temperature of $313.4 \mathrm{~K}$ for a thermal conductivity of $\lambda_{\text {earth }}=0.658 \mathrm{~W} / \mathrm{K}^{-1} \cdot \mathrm{m}^{-1}$. By way of comparison the roof terrace offers better indoor temperature of the habitat.

Whatever the variations in the geometric parameters of the three roof models, materials with low thermal conductivity are those that generate the lowest temperatures within the habitat. The results show that the compressed earth roof terrace shows a satisfactory thermal behavior. However, the temperatures of the different media of each roof decrease as geometric parameters increase. The effectiveness of a roof to reduce the interior temperature of a room is related to its geometric shape and physical properties. This digital study results in an endogenous solution on heat transfer of three roof models in hot and dry climates. Our results also show that the choice of roof of a habitat has a significant impact on thermal comfort. It is always considered as the main element of the thermal 
regulation of the heat exchange between the interior and the exterior. This leads us to say that the roof terrace is the most suitable for the hot and dry climate that is that of Burkina. As a result, this work contributes to the awareness and promotion of local materials.

\section{Conflicts of Interest}

The authors declare no conflicts of interest regarding the publication of this paper.

\section{References}

[1] Hamida, B. (2007) Study and Realization of a Passive Cooling System in Using a Radio-Evaporatory Roof in Arid Warm Climates. Mentouri University of Constantine, Constantine.

[2] Kieno, P.F. (1985) Theoretical and Experimental Study of a Heat Pipe System for Air Conditioning in Hot and Dry Countries. University of Nice, Nice.

[3] Ouedraogo, I. (2009) Modelling and Optimization of a Bioclimatic Roof for the Passive Air Conditioning of a Typical Habitat of Burkina Faso. University of Ouagadougou, Ouagadougou.

[4] Sam, F. (2012) Thermal Rehabilitation of a Premises in an Arid-Case Area of Ghardia. Mouloud Mammeril University of Tizi Ouzou, Tizi Ouzou.

[5] Ouattara, F., Toure, S., Memeledje, A. and Museruka, C. (2004) Theoretical and Experimental Study of Heat Transfer in a Geoconcrete Round Cell. Journal of Science, 4.

[6] Mazari, M. (2012) Study and Evaluation of Thermal Comfort in Public Buildings: Case Study of the Architecture Department of Tamda (Tizi-Ouzou). Mouloud Mammeri University of Tizi Ouzou, Tizi Ouzou.

[7] Dalel, M. (2006) Impact of Thermal Inertia on Hygrothermal Comfort and Energy Consumption of the Building: Case of Colonial Housing in Guelma, Memory of Magistere. Mentouri University of Constantine, Constantine.

[8] Toguyeni, D., Coulibaly, O., Ouedraogo, A., Koulidiati, J., Dutil, Y. and Rousse, D.R. (2012) Study of the Influence of Local Insulating Roof Materials on the Air-Conditioning Loads of an Individual House Made of Straw Clay, CIFEM Art-13-93.

[9] Rebha, G. (2013) Elaboration of a Building Material for the Thermal Insulation of Buildings. Kasdi Merbah Ouargla University, Ouargla.

[10] Meukam, P. (2004) Upgrading of Stabilized Earth Bricks for Thermal Insulation of Buildings. State-Joint Thesis between the University of Cergy-Pontoise and the University of Yaoundé I.

[11] Jannot, Y. and Djiako, T. (1994) Energy Saving and Thermal Comfort in Tropical Habitat. International Journal of Refrigeration, 17, 166-173. https://doi.org/10.1016/0140-7007(94)90015-9

[12] Awanou, C.N., Kieno, P.F. and Berger, X. (1987) Air Conditioning in Hot and Dry Countries by Roof Diode. Revue Physique Appliquée, 22, 413-423.

https://doi.org/10.1051/rphysap:01987002206041300 


\section{Abbreviations}

$C p:$ Heat capacity $\left(\mathrm{J} \cdot \mathrm{kg}^{-1} \cdot \mathrm{K}^{-1}\right)$

Ep: Thickness (m)

$h r$. Coefficient of heat transfer by natural convection between a wall and the fluid that circulates in its vicinity. $\left(\mathrm{W} \cdot \mathrm{m}^{-2} \cdot \mathrm{K}\right)$

hc. Coefficient of heat transfer by radiation between two walls $\left(\mathrm{W} \cdot \mathrm{m}^{-2} \cdot \mathrm{K}\right)$

M: Mass (kg)

T: Temperature (K)

$t$ time (s)

grec symbols

$\lambda$ : Thermal conductivity $\left(\mathrm{W} \cdot \mathrm{m}^{-2} \cdot \mathrm{K}\right)$

$\Delta t$ : Time step (s)

Indice

ce: Exterior face of roof tile

$c i$ : Roof tile inside face

se: Exterior face of roof terrace

si: Interior face of roof terrace

vc. celestial vault

sol: sol

$a m b$ : Ambiance

a: Confined air between roof and false ceiling

$p i$ inside of ceiling

pe: outside of ceiling 